\title{
Correlation of Reticulocyte Hemoglobin Equivalent (Ret-He) Levels and Iron Deficiency Anemia in CKD Patients Treating Regular Hemodialysis
}

\author{
Husni Gunawan Hasibuan ${ }^{1}$, Syafrizal Nasution ${ }^{2}$, Radar Radius Tarigan ${ }^{2}$ \\ ${ }^{1}$ Department of Internal Medicine, Faculty of Medicine, Universitas Sumatera Utara, Medan, Indonesia \\ ${ }^{2}$ Division of Nephrology and Hypertension, Department of Internal Medicine, Faculty of Medicine, \\ Universitas Sumatera Utara, Medan, Indonesia \\ Corresponding Author: Husni Gunawan Hasibuan
}

\begin{abstract}
Background: Anemia appears in the early stages of CKD and its prevalence increases as kidney function declines. Ret-HE can be used to diagnose iron-deficiency anemia. Indonesia does not yet have appropriate research data on RET$\mathrm{He}$ levels in CKD patients undergoing hemodialysis as a parameter to assess iron. Therefore, this study aims to examine the ability of RET-He as an alternative parameter to assess iron deficiency in hemodialysis patients.

Method: This research is a correlation analytic study with a cross-sectional design, carried out in February-May 2021 at the Hemodialysis Installation of H. Adam Malik Hospital. Blood sample collection and examination are carried out at the Clinical Pathology Laboratory. Primary and secondary data were collected from interviews, questionnaires, or patient medical records. The data will be analyzed by Pearson correlation test using SPSS software.
\end{abstract}

Results: A total of 41 samples consisted of 31 anemic patients and 10 anemic patients with normal RET-He levels. Demographic characteristics based on age group with an average of $47 \pm 13.28$ years. The correlation of Ret-HE and TSAT levels in CKD patients undergoing hemodialysis shows a significance value of 0.000 , so it can be concluded that there is a correlation between RET-HE and TSAT levels with a significance value of $<0.05$. According to the Pearson correlation number of 0.618 which is in the range of 0.61 to 0.80 .

Conclusion: There is a positive correlation between Ret-HE levels and iron deficiency anemia in CKD patients undergoing regular hemodialysis.

Keywords: CKD, RET-HE, Hemodialysis

\section{INTRODUCTION}

Chronic kidney disease (CKD) affects between $8 \%$ and $16 \%$ of the population worldwide. Globally, CKD is most commonly associated with diabetes and/or hypertension, but other causes such as glomerulonephritis, infections, and environmental exposures (such as air pollution, herbal remedies, and pesticides) are common in Asia, sub-Saharan Africa, and other developing countries. ${ }^{[1]}$

CKD resulted in 1.2 million deaths in 2017. An additional 1.4 million deaths from cardiovascular disease were caused by impaired kidney function, representing $7.6 \%$ of deaths from cardiovascular disease in 2017. ${ }^{[2]}$ IRR (Indonesian Renal Registry) data from 651 renal units reported, there were 132,142 patients actively undergoing dialysis in 2018, most are patients with CKD. ${ }^{[3]}$

Anemia appears in the early stages of CKD and its prevalence increases with decreasing kidney function. The etiology of anemia in CKD patients is multifactorial. Major contributing factors include absolute or functional iron deficiency; relative erythropoietin deficiency, deficiency of micronutrients such as folic acid and B- 
complex vitamins, chronic inflammation, infection, blood loss after extracorporeal circulation, blood collected for examination purposes, and hemolysis. ${ }^{[4]} \mathrm{A}$ CKD patient on hemodialysis (HD) loses about 1-2 g iron per year through this mechanism.

Reticulocyte $\mathrm{Hb}$ equivalent (RET$\mathrm{He})$ levels $<25 \mathrm{pg}$ indicate classic iron deficiency and also predict functional iron deficiency in those receiving Erythropoiesis Stimulating Agent (ESA) therapy. RET-He value $<306 \mathrm{pg}$ seems to be the best predictive value for the possible response to intravenous iron therapy in chronic kidney disease (CKD) patients undergoing hemodialysis. ${ }^{[5]}$ RET-He, a new hematological parameter in routine blood tests, and may play an important role in the differential diagnosis of hypochromic microcytic anemia. ${ }^{[6]}$

Several previous studies have reported the usefulness of RET-He as a parameter for evaluation of iron status. A study byEtienne et al. compared Ret-He parameters in iron deficiency anemia with anemia of chronic disease. The results showed that Ret-He was significantly lower in iron deficiency anemia than in anemia of chronic disease. Ret-He can be used to diagnose iron-deficiency anemia with a sensitivity of $85 \%$ and specificity of $69 \%$. $^{[7]}$ Until now, Indonesia does not have appropriate research data on RET-He levels in CKD patients undergoing hemodialysis as a parameter to assess the target of iron supplementation. Similar studies were conducted in Italy and Japan, the RET-He values were found to be different in the two populations, so further studies to determine the RET-He parameters need to be carried out in the Indonesian population. ${ }^{[8]}$ This study aims to examine the ability of RET$\mathrm{He}$ as an alternative parameter to assess iron deficiency in hemodialysis patients.

\section{METHODS}

This is a correlation analytic study with a cross-sectional research design. The research was carried out from February to May 2021 at the Hemodialysis Installation of H. Adam Malik Hospital with the approval of the USU Medical Faculty Research Ethics Commission. The collection and examination of blood samples were carried out by the Clinical Pathology Laboratory of RSUP H. Adam Malik.

The number of samples was 41 patients who met the inclusion and exclusion criteria. Inclusion criteria were CKD patients undergoing regular hemodialysis ( $\geq 3$ years) and aged 18 years. While the exclusion criteria were patients who received iron supplements, both oral and intravenous in the last 3 months, bleeding events (vomiting blood, bloody stools, nosebleeds, bleeding gums) in the last 4 weeks in the medical record, patients receiving blood transfusions (whole blood or packed red blood cell) in the last 4 weeks in the medical record, and evidence of malignancy recorded in the medical record at the time of examination of the initial data of the study.

Subjects who met the criteria were explained and if they agreed, they would be asked to give written informed consent to participate in the study. Primary and secondary data collected from interviews, questionnaires, or patient medical records to determine the patient's age, history of primary skin disease, and duration of hemodialysis, and blood tests were carried out to obtain Hemoglobin ( $\mathrm{Hb})$, Serum Iron (SI), Total Iron Binding Capacity (TIBC), Ferritin, Ret-He.

Data analysis using SPSS software aims to see the correlation of RET-He and TSAT levels using the Pearson correlation test if the two groups of data are normally distributed and if not normally distributed, the Spearman correlation test is used. All statistical tests with $\mathrm{p}<0.05$ were considered significant. Assess the cut-off from Ret He by using the ROC curve.

\section{RESULTS \\ Characteristics of Subjects}

In this study, a total of 41 patients were included in the study, consisting of 31 
Husni Gunawan Hasibuan et.al. Correlation of reticulocyte hemoglobin equivalent (Ret-He) levels and iron deficiency anemia in CKD patients treating regular hemodialysis

anemic patients and 10 anemic patients with normal RET-He levels.

Table 1: Characteristics of subjects
\begin{tabular}{|c|c|}
\hline Characteristics & $\mathrm{n}=41$ \\
\hline Age (years) & $47+13.28$ \\
\hline Man & $25(61 \%)$ \\
\hline Woman & $16(39 \%)$ \\
\hline $\mathrm{Hb}(\mathrm{g} / \mathrm{dL})$ & $7.68+1.26$ \\
\hline $\mathrm{SI}(\mu \mathrm{g} / \mathrm{dL})$ & $44.73+35.61$ \\
\hline $\mathrm{TIBC}$ & $219.44+62.32$ \\
\hline Ferritin $(\mathrm{ng} / \mathrm{mL})$ & $8.08+8.47$ \\
\hline $\mathrm{TSAT}$ & $21.85+20.08$ \\
\hline Ret-HE $(\mathrm{pg})$ & $30.55+5.18$ \\
\hline
\end{tabular}

\section{Correlation of Reticulocyte Hemoglobin} Equivalent (Ret-He) Levels and Iron Deficiency Anemia in CKD Patients undergoing Hemodialysis

The normality test of the data was carried out using the Kolmogorov-Smirnov test, which if the results obtained a significance value of $>0.05$ on the residual value, it can be concluded that the data is normally distributed. From the results of the normality test, it is known that the significance value is $0.145>0.05$, so it can be concluded that the residual value is normally distributed. Then the Pearson correlation test can be continued to determine the correlation between TSAT and Ret-HE.

Table 2: Correlation of Ret-HE and TSAT levels in CKD patients undergoing hemodialysis

\begin{tabular}{|l|c|c|c|}
\hline Variable & Rate & r & P \\
\hline TSAT & $21.85+20.08$ & 0.618 & $0.000^{*}$ \\
\hline Ret-He & $30.55+5.18$ & & \\
\hline \multicolumn{4}{|c}{ "Pearson correlation test } \\
\end{tabular}

Table 2 shows a significance value of 0.000 , so it can be concluded that there is a correlation between RET-HE and TSAT levels with a significance value of $<0.05$. Based on the Pearson correlation number of 0.618 which is in the range of 0.61 to 0.80 , it can be concluded that there is a statistically strong correlation between the two variables.

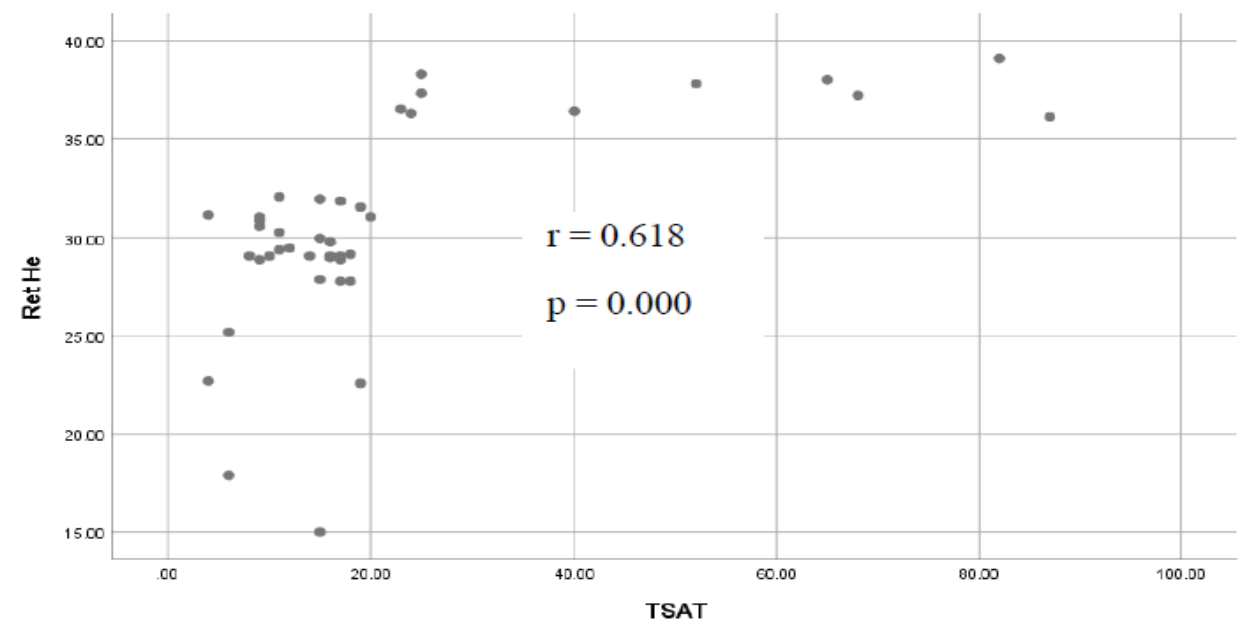

Figure 1: Scatter plot correlation of Ret He and TSAT levels. There is a positive correlation between Ret He and TSAT levels in CKD patients undergoing hemodialysis.

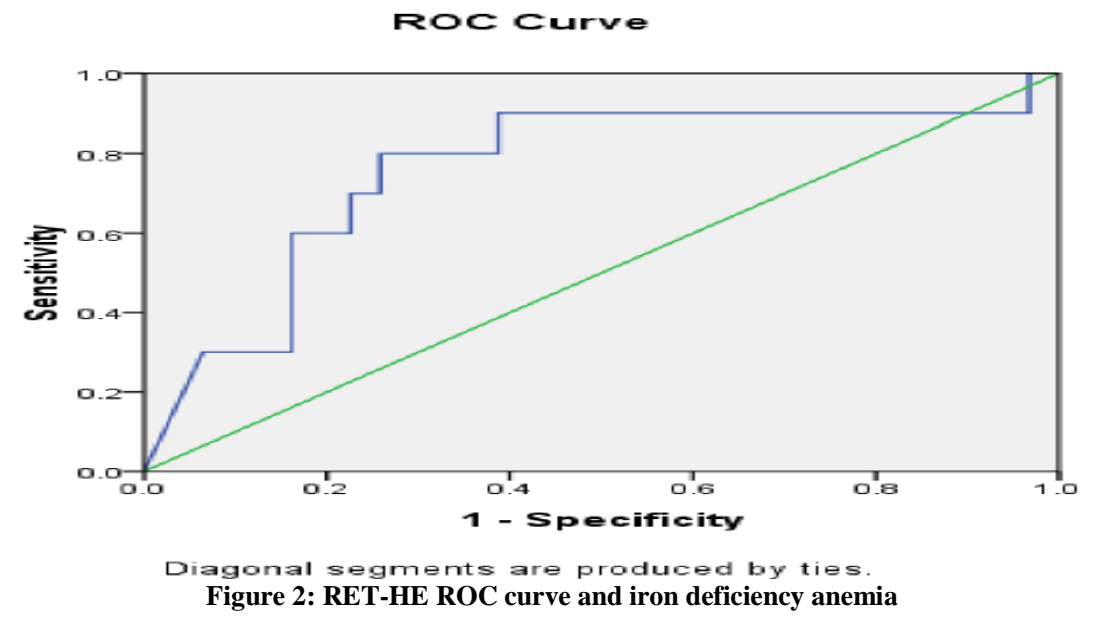


Husni Gunawan Hasibuan et.al. Correlation of reticulocyte hemoglobin equivalent (Ret-He) levels and iron deficiency anemia in CKD patients treating regular hemodialysis

ROC analysis was performed to evaluate the ability to detect iron deficiency in RET-He. From the entire study sample, there were 31 people with low RET-He levels of 41 people. When the cut-off level of RET-He was determined to be 32.05 (pg), a sensitivity of $100 \%$ was found with a specificity of $96 \%$.

Table 3: Coordinates of ROC Curve

\begin{tabular}{|c|c|c|}
\hline Cut Off & Sensitivity (\%) & Specificity (\%) \\
\hline 28,400 & 1,000 & .258 \\
\hline 29,150 & 1,000 & .516 \\
\hline 30150 & 1,000 & .677 \\
\hline 31,000 & 1,000 & .774 \\
\hline 32.050 & 1,000 & .968 \\
\hline
\end{tabular}

* The smallest cut-off value is the minimum observed test value minus 1 , and the largest cut-off value is the maximum observed test value plus 1 . All other cut off values are the average of two consecutive ordered observed test values.

\section{DISCUSSION}

In this study, a sample of 41 patients consisted of 31 anemic patients and 10 anemic patients with normal RET-HE levels. There were 25 men $(61.0 \%)$ and 16 women (39.0\%). Based on the demographics of the age group, the average age was $47 \pm 13.28$ years with the number of subjects not significantly different between men and women. This study is in line with research by Rovani et al. (2016) at Dr. Hospital. Wahidin Sudirohusodo Makasar reported that there was no significant difference between male and female patients $(53.3 \%$ and $46.6 \%)$. ${ }^{\text {[rror! Reference source not found.] }}$

Kidney failure is a clinical condition characterized by an irreversible decline in kidney function, to a degree that requires permanent renal replacement therapy, in the form of dialysis or transplantation kidney. ${ }^{[2,6]}$ Anemia is found in most patients with CKD, especially in patients undergoing hemodialysis. Anemia is usually defined as a circulating hemoglobin level of less than $12 \mathrm{~g} / \mathrm{dl}$ in women or $14 \mathrm{~g} / \mathrm{dl}$ in men or a hematocrit of less than $37 \%$ in women or $40 \%$ in men. The United States Renal Data System (USRDS) 2010 reported the incidence of anemia in CKD stages 1-4 was
$51.8 \%$ and the mean hemoglobin in endstage renal disease was $9.9 \mathrm{~g} / \mathrm{dl}$. Cipto Mangunkusumo Hospital, Jakarta (2010) reported that all hemodialysis patients were anemic with average hemoglobin of 7.7 g/dl. H.Adam Malik Hospital, North Sumatra (2011) reported CKD patients on routine hemodialysis with an average $\mathrm{Hb}$ of $8.9 \mathrm{~g} / \mathrm{dl} .{ }^{[9]}$ In 41 patients suffering from CKD in this study, the hemoglobin level was on average of $7.68 \pm 1.26 \mathrm{~g} / \mathrm{dl}$.

It is important to distinguish between absolute (or storage) iron deficiency and functional (or relative) iron deficiency. In absolute iron deficiency, the body's total iron stores are depleted, limiting the production of red blood cells. Factors contributing to absolute iron deficiency include decreased gastrointestinal absorption in CKD patients and increased blood loss (e.g. in the setting of uremiainduced platelet dysfunction and iatrogenic loss from serial blood draws or site and circuit access problems during dialysis procedures). ${ }^{[10]}$ Patients with CKD also may have functional iron deficiency anemia, which occurs in the setting of erythropoiesis induced during ESA use. The second is caused by chronic inflammatory anemia, known as reticuloendothelial cell iron block. ${ }^{[4]}$

Conventional methods for diagnosing iron deficiency involve measurement of serum iron, ferritin levels, and TSAT, but both are indirect markers. ${ }^{[11]}$ Among these, serum ferritin, which reflects the total amount of body iron stores, is a universally available and standardized measurement and is the most effective test for detecting iron deficiency. However, false-positive serum ferritin values can be observed because they are influenced by inflammation or inflammation, malignancy, or liver disease. ${ }^{[12]}$ Serum iron and TIBC were used to calculate the percentage transferrin saturation (TSAT). Values below $20 \%$, and certainly below $18 \%$, indicate an inadequate supply of iron for hemoglobin synthesis and red blood cell production. Plasma transferrin is a glycoprotein with 
Husni Gunawan Hasibuan et.al. Correlation of reticulocyte hemoglobin equivalent (Ret-He) levels and iron deficiency anemia in CKD patients treating regular hemodialysis

two iron-binding domains and is synthesized by the liver. It is the most important vehicle for transporting iron into cells and preventing iron-mediated free radical toxicity. In the treatment of CKD patients, low TSAT $(<20 \%)$ combined with low serum ferritin is diagnostic of absolute iron deficiency. A low TSAT combined with normal or high serum ferritin is diagnostic of functional iron deficiency. ${ }^{[13]}$

In general, serum ferritin $<100$ $\mathrm{ng} / \mathrm{mL}$ and/or TSAT $<20 \%$ is defined as absolute iron deficiency and serum ferritin $100 \mathrm{ng} / \mathrm{mL}$ and/or TSAT $<20 \%$ is considered functional iron deficiency. In CKD patients, serum ferritin levels for absolute iron deficiency are higher as a result of chronic inflammation, infection, malnutrition, or malignancy and not always due to iron overload. ${ }^{[13]}$ In this study, the mean serum ferritin level was $8.08 \pm 8.47$ $\mathrm{ng} / \mathrm{ml}$ and transferrin saturation levels (TSAT) with an average of $21.85 \pm 20.08 \%$. Serum Iron (SI) levels with an average of $44.73 \pm 35.61 \mathrm{~g} / \mathrm{dl}$. Total Iron Binding Capacity (TIBC) levels with an average of $219.44 \pm 62.32 \mathrm{~g} / \mathrm{dl}$.

Various studies were conducted to find the best parameters in assessing iron status, including the percentage of hypochromic RBC (\%HRC), reticulocyte hemoglobin content $(\mathrm{CHr})$, soluble transferrin receptor (sTfR), plasma neutrophil gelatinase-associated lipocalin (NGAL), Hepcidin. ${ }^{[14]} \mathrm{CHr}$ and RET-He measure the amount of iron contained in reticulocytes. Thus, the assay can be used to estimate iron availability for erythropoiesis. ${ }^{[15]}$ Reticulocyte Hemoglobin Equivalent (Ret-He), introduced by Sysmex, is an alternative measure of hemoglobin mass in reticulocytes. Several studies have found a strong correlation between Ret-He and $\mathrm{CHr}$ in iron-deficient CKD patients.

A study conducted by Sany et al (2020) described an average level of Ret-HE of $25.84 \pm 4.23 \mathrm{pg}$ in CKD patients undergoing HD. ${ }^{[16]}$ This is not much different from the results in this study that reported levels of Reticulocyte Hemoglobin
Equivalent (Ret -HE) with an average of $30.55 \pm 5.118$ pg. From the Pearson TSAT and Ret-HE correlation table obtained a significance value of 0.000 , it can be concluded that there is a relationship between Ret-HE and TSAT levels with a significance value of $<0.05$. According to the Pearson correlation number of 0.618 which is in the range of 0.61 to 0.80 , it can be concluded that there is a strong correlation between the two variables. This is in line with the study conducted by Miwa et al. (2010) which showed a good correlation between RET-He and TSAT $(\mathrm{r}=0.543, \mathrm{p}<0.01) .^{[14]}$ RET-He measures hemoglobin in reticulocytes that are released from the bone marrow approximately 18 to 36 hours before they form into mature erythrocytes. Therefore, the RET-He parameter offers a direct index of iron availability. Thus, RET-He has considerable ability to provide highaccuracy readings of the iron status of HD patients. ${ }^{[17]}$ In this study, a strong correlation was observed between Ret-HE and TSAT.

ROC analysis was performed to evaluate the ability to detect iron deficiency anemia using the RET-He value according to the diagnostic criteria for iron deficiency anemia (TSAT < 20\%). Data from cases were analyzed to determine the cut-off level of Ret-He, there were 31 people with lower RET-He levels out of 41 people. When the cut-off level of RET-He was determined to be $16.0,20.0$, and $22.0(\mathrm{pg})$, a sensitivity of $100 \%$ was found with a specificity of $96 \%$, 93\%, 90\%, respectively. Previous study reports by Canals et al. (2005), Brugnara et al. (2006), Grazia et al. (2007), Maconi et al. (2008), Miwa et al. (2010), Urrechaga et al. (2011), and Buttarello et al. (2010) found a good diagnostic performance of RET-He in the diagnosis of iron deficiency anemia with various cutoff levels between 25-32.4 pg. In this study, reported the usefulness of the Ret-HE parameter as an index of iron status in HD patients. This finding is in agreement with another study, in which RET-He showed excellent diagnostic 
Husni Gunawan Hasibuan et.al. Correlation of reticulocyte hemoglobin equivalent (Ret-He) levels and iron deficiency anemia in CKD patients treating regular hemodialysis

performance and was generally superior for the diagnosis of iron deficiency anemia among HD patients when compared with traditional parameters, with a cut-off rate of $32.0(\mathrm{pg})$.

\section{CONCLUSION}

There is a positive correlation between Ret-HE levels and iron deficiency anemia in CKD patients undergoing regular hemodialysis, transferrin saturation values were found.

The cut-off value as a predictor of iron deficiency in CKD patients undergoing regular hemodialysis was 32.0 (pg), a sensitivity of $100 \%$ was found with a specificity of $96 \%$.

\section{Acknowledgement: None}

\section{Conflict of Interest: None}

Source of Funding: None

Ethical Approval: Approved

\section{REFERENCES}

1. Chen TK, Knicely DH, Grams ME. Chronic Kidney Disease Diagnosis and Management. JAMA. 2019;332(13):12941304

2. Bikbov B, Purcell C, Levey AS, Smith M, Abdoli A, et al. Global, regional, and national burden of chronic kidney disease, 1990-2017: a systematic analysis for the Global Burden of Disease Study 2017. The Lancet. 2020;395:709-33

3. IRR. 11th Report of Indonesian Renal Registry. In. Indonesia. 2018

4. Plastina JCR, Obara VY, Barbosa DS, Morimoto HK, Reiche EMV, et al. Functional iron deficiency in patients on hemodialysis: prevalence, nutritional assessment, and biomarkers of oxidative stress and inflammation. Braz. J. Nephrol. (J. Bras. Nefrol). 2019;41(4):472-480

5. Lian Y, Shi J, Nie N, Huang Z, Shao Y. Et al. Reticulocyte Hemoglobin Equivalent (Ret-He) Combined with Red Blood Cell Distribution Width Has a Differentially Diagnostic Value for Thalassemias. Hemoglobin. 2019

6. Urrechaga E, Boveda O, Aguayo FJ, De La Hera P, Munoz RI, et al. Percentage of hypochromic erythrocytes and reticulocyte hemoglobin equivalent predictors of response to intravenous iron in hemodialysis patients. Int. Jnl. Lab. Hem. 2016;38:360365

7. Brugnara C, Schiller B, dan Moran J. Reticulocyte hemoglobin equivalent (Ret $\mathrm{He})$ and assessment of iron-deficient states. Clin Lab Haematol. 2006 Oct; 28(5): 303308. DOI: $10.1111 /$ j.1365-2257.2006. 00812.x

8. Wirawan R, Tedja AT, Herinka F, dan Lydia A. Concordance between Reticulocyte Hemoglobin Equivalent and Reticulocyte Hemoglobin Content in CKD Patients Undergoing Hemodialysis. Acta Med Indones - Indones J Intern Med. 2017; 49(1): 34 - 40.

9. Gaweda AE. Markers of iron status in chronic kidney disease. Hemodial Int. 2017;21 Suppl 1(Suppl 1):S21-S27. doi:10.1111/hdi.12556

10. Wirawan R, Tedja AT, Herinka F, dan Lydia A. Concordance between Reticulocyte Hemoglobin Equivalent and Reticulocyte Hemoglobin Content in CKD Patients Undergoing Hemodialysis. Acta Med Indones - Indones J Intern Med. 2017; 49(1): 34 - 40.

11. Koury MJ, Haase VH. Anaemia in kidney disease: harnessing hypoxia responses for therapy. Nat Rev Nephrol. 2015;11(7): 394410

12. Miwa N, Akiba T, Kimata N, Hamaguchi Y, Arakawa $\mathrm{Y}$, et al. Usefulness of measuring reticulocyte hemoglobin equivalent in the management of haemodialysis patients with iron deficiency. Int. Jnl. Lab. Hem. 2010;32:248-255

13. Toki Y, Ikuta K, Kawahara Y, Niizeki N, Kon $\mathrm{M}$, et al. Reticulocyte hemoglobin equivalent as a potential marker for diagnosis of iron deficiency. Int J Hematol. 2017

14. Batchelor EK, Kapitsinou P, Pergola PE, Kovesdy CP, Jalal DI. Iron Deficiency in Chronic Kidney Disease: Updates on Pathophysiology, Diagnosis, and Treatment. JASN. 2020;31:456-468

15. Bargman JM, Skorecki K. Chronic Kidney Disease. In: Harrison TR, Resnick WR, Wintrobe MM, Thorn GW, Adams RD, eds. Harrisons Principles of Internal Medicine. 19th ed. London: McGraw-Hill Education's Professional Publishing; 1811-20 
Husni Gunawan Hasibuan et.al. Correlation of reticulocyte hemoglobin equivalent (Ret-He) levels and iron deficiency anemia in CKD patients treating regular hemodialysis

16. Suwirta K. Penyakit Ginjal Kronik. In: Setiati S, Alwi I, Sudoyo AW, K MS, Setiyohadi B, Syam AF, eds. Buku Ajar Ilmu Penyakit Dalam. VI ed. Jakarta Indonesia: InternaPublishing; 2014:2159

17. Dahlan MS, Epid M. Besar Sampel dan Cara Pengambilan Sampel. III ed. Jakarta: Salemba Medika; 2013:46

18. Rovani F, Nurulita A, Arif M. Analysis of Ret-He in Chronic Kidney Disease Patients at Dr. Wahidin Sudirohusodo Hospital Makassar. Indonesian Journal of Clinical
Pathology and Medical Laboratory. 2018;25(1):7-10

How to cite this article: Hasibuan HG, Nasution $\mathrm{S}$, Tarigan RR. Correlation of reticulocyte hemoglobin equivalent (Ret-He) levels and iron deficiency anemia in CKD patients treating regular hemodialysis. International Journal of Research and Review. 2021; 8(11): 10-16. DOI: https://doi.org/10.52403/ijrr.20211102 